and potentially flawed procedure. Pressman's main point is that much of the condemnation of leucotomy has taken no account of its history, in that it ignores the clinical and administrative problems faced by those who used it and has an unreal view of the actual process of medical advance. This cannot always be on the basis of scientific deduction. But when Pressman finally asks "Did it work?", the issue is evaded.

From reading this work, one would conclude that the leucotomy story ended in about 1955, but this is not so. 'Modified' operations, with much more limited effects, continued to be used in Europe for intractable cases of depression and obsessive-compulsive disorder until they were largely replaced by more recent drugs. Sometimes they really did save lives. But Pressman makes hardly any reference to work outside the United States, giving only a passing mention to a British 1947 survey of 1,000 cases, which was at the time the largest and most systematic research carried out. He tells us how to read the story, but not how it ended, even though the text is long and repetitious.

Regrettably, Pressman died shortly after finishing this work. Had he lived, he would undoubtedly have made further important contributions to medical history.

Hugh Freeman is at 21 Montague Square, London W1H 1RE, UK.

\section{Genera obscura}

\section{The Platypus and the Mermaid: And Other Figments of the Classifying Imagination}

by Harriet Ritvo

Harvard University Press: 1997. Pp. 288. $£ 19.95, \$ 29.95$

\section{Peter J. Bowler}

Harriet Ritvo's book about the Victorians' efforts to classify the world of animal life is fascinating but ultimately frustrating. This is not a history of scientific taxonomy as such, although it does deal in part with biologists' efforts to confront the unusual and the exotic. Human beings always seek to impose order on diversity, but who decides the categories to be imposed, and how do we deal with the exceptions that nature all too frequently provides? Scientific naturalists regarded it as their task to classify the animal kingdom, but they had to shift their ground in the face of newly discovered species that did not fit into existing schemes, to say nothing of hybrids and monstrostities.

In the course of Ritvo's story we meet eminent figures such as Charles Darwin and Richard Owen, but also a host of lesser scientific names now shrouded in obscurity. We also meet rival communities vying for the right to impose categories of their own, including breeders, hunters, cooks and even railway companies. The cartoon used as a frontispiece shows a railway porter informing an old lady that cats, rabbits and parrots are counted as dogs, whereas her tortoise is an insect (and so, presumably, travels free).

Ritvo starts with the world of scientific taxonomy, pointing out the tensions even here between the rival methods of describing, naming and classifying species. The order that was supposed to have been imposed by the Linnean system turned out to be illusory, and in the early nineteenth century there were bitter debates between various schools of thought. But all the systems had to allow for the inclusion of exotic species that did not fit into the traditional categories, and it is here that we meet the platypus. An oviparous mammal was such a novelty that Owen at first refused to accept popular accounts that it laid eggs, and it was only in 1884 that W. H. Caldwell was able to confirm the stories and describe the eggs.

Ritvo breaks off at this point, paying no attention to the debates that raged among evolutionists trying to use both the monotremes and the marsupials as models for stages in mammalian phylogeny. Because 'missing links' were even more interesting if they were still alive, this area would have added another dimension to the story, and would have amplified the value-laden nature of the scientists' efforts to confront animals that seemed to inhabit the shadowy world between the major phyla.

A chapter on domesticated animals illustrates the tensions that could arise between the breeder and the scientist. The naturalists' binomial nomenclature was often ignored or even ridiculed by the practical men who dealt with horses, dogs and cattle every day. Some breeds achieved fame because they were thought to embody the original form of the wild ancestor from which domesticated varieties had arisen.

Hybrids were another popular topic, of great interest to Darwin. Ritvo recounts the complex lore of Victorian beliefs, observations and experiments on the question of how distinct races or even species could cross. This was not confined to animals: in an age acutely conscious of the alleged differences between the human races, the status of mulattoes and half-breeds was of perennial concern. Distinctive 'types' could be found (it was claimed) even among the inhabitants of the different English counties, although most of the population was, of course, by that time mixed.

Monstrosities, however defined, were a source of fascination to both scientists and the general public. Ritvo focuses mostly on attitudes towards, and ideas about, human deformities. Many unfortunates with gross

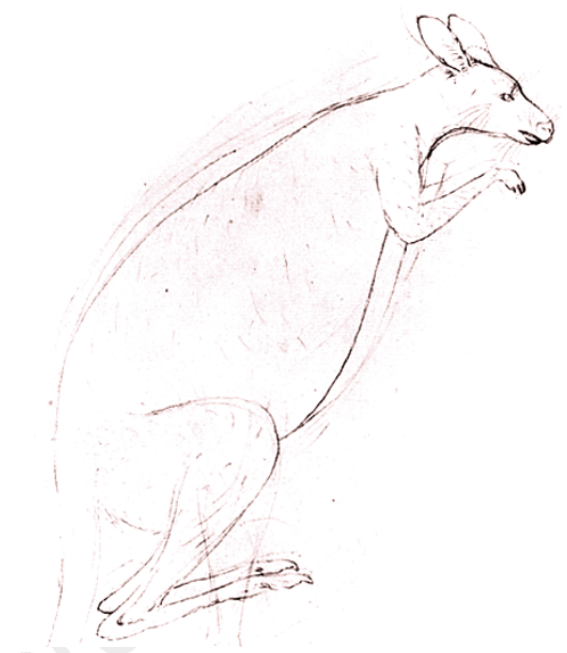

Jumping to conclusions...

bodily deformities were condemned to a life in shows and circuses, and, although a science of teratology emerged, it could do little to impose order on so bizarre a range of abnormal structures. Some individuals were seen almost as monsters even though they were merely unusually tall or fat. As a Leicester man, I was pleased to see the illustration of Daniel Lambert, perhaps the fattest man of his time, who evaded the worst experiences of the 'freak show' and was able to chat affably with his fashionable visitors.

It is in this chapter that the mermaid finally makes her (or rather its) appearance, because by this time the idea of a natural race of human-fish intermediates had been abandoned by all but the most vulgar. Specimens of mermaids were presented both to the public and to science, but were regarded as monstrosities, at least until they were exposed as frauds. Curiously, it is in this context that we meet a marine anomaly that was for a time a more serious bone of contention between scientists and other professionals. The sea serpent was sometimes portrayed as a relic of prehistoric times, but scientists such as Owen were anxious to discount it because they wanted to discredit the unsystematic observations of naval officers and the like.

Ritvo's book is a mine of fascinating information that will interest historians of both science and popular culture, although the former will sometimes be disappointed by its failure to follow through into a discussion of related issues, such as the roles of both intermediates and monstrosities in the emergence of evolutionary theory. More generally, the book's framework of analysis is less than satisfying because it is difficult to see a coherent pattern in the wealth of detail presented. The various discourses attempting to classify the variety of nature are themselves almost impossible to classify.

Peter J. Bowler is in the Department of Social Anthropology at Queen's University, Belfast BT7 1NN, UK. 